\title{
COLLOQUIA
}

\author{
Wojciech Sajkowski \\ Faculty of History \\ Adam Mickiewicz University in Poznan, Poznań \\ wojciech.sajkowski@amu.edu.pl

\section{Introduction to the Thematic Section}

7 he images of the borders of civilizations is the main topic of the papers it was emphasised that this issue is particularly important, because the notion of civilization is strictly related to the issue of borders, since it would became meaningless without the opposition to another civilization, or the lack of it. The juxtaposition between the notion of civilization and its different antinomies seems easier to display when seen from its centre, however the shape of its border is not always clear, even if it has a foundation in clear geographical or political divisions. Thus, this border can be represented as a linear frontier between a civilized state and barbaric lands, or as a borderland which encompasses some kind of fluent transition. The civilization border can be also represented in a macro scale, shaping geographic divisions of the continents (as it was in the case of the Balkans), but its depiction can also concern the micro scale, for example the difference between an urban and a natural landscape. The notion is even broader, because it is not only treated in the context of space but also social behaviours and their evolution (which, since the Enlightenment, is bound to the notion of progress). The question of establishing the difference between the civilized and the uncivilized is still shaping the identity of modern societies, and thus it is worth attention.

This is an Open Access article distributed under the terms of the Creative Commons Attribution 3.0 PL License (creativecommons.org/licenses/by/3.0/pl/), which permits redistribution, commercial and non-commercial, provided that the article is properly cited. ( The Author(s), 2017

Publisher: Institute of Slavic Studies, Polish Academy of Sciences

Editor-in-chief: Jolanta Sujecka

Conception and academic editing of this issue: Wojciech Sajkowski

with the collaboration of Jolanta Sujecka 
The articles which we received as feedback to our call for papers develop many of the above-mentioned issues, but also signalize new problems. Some of the articles represent the problem of the borders of civilisations in the perspective of the history of the culture. Such is the case of the paper by Filip Jakubowski, who presents the problem of the reality of the borderlands which existed between the Muslim and the Christian world on the example of the daily life of Muslim Spain and Portugal of medieval ages. In this case the border of civilization was in fact a sphere of contact and transition. A similar approach was presented by Tomasz Ewertowski in his article on Northeast China as a Contact Zone in Polish and Serbian Travelogues, although this paper focused not on the question of borderland in itself, but rather on its representation made by travellers. Here, the emphasis was also put on the aspect of the border of civilisation as a sphere of fluent transition, visible especially in the "transcultural phenomena of everyday life".

The problem of the representation appears also in Paweł Michalak's paper on the perception of Yugoslav-Bulgarian relations in the Serbian newspaper "Politika" in the first part of 1930s. The article shows the case of two nations which were, in theory, culturally close to each other, but the depictions of their political relations in the media often recalled the cultural differences and the attempts to overpass them, e.g. by the promotion of national art.

Art appeared also in Karolina Majkowska's paper, which focuses on the field of contemporary Dominican-American literature. Unlike in the previously mentioned article, where art was mentioned only as an object of national politics, Majkowska showed how this notion can surpass political and national context. The author presents literature as a platform which allows us to reject the notion of the border, because it can create the space of in-betweenness which escapes cultural and political borders.

In the above-mentioned examples the problems of the borders of civilization were literally related to the geographic borders of the political structures belonging to the various cultural spaces, although those borders could also transgress the chorological axis of the one political and cultural entity. Such a case is presented in the article by Tomasz Rawski and Katarzyna Roman-Rawska on the Russian national cinema after 2005, which depicts how different episodes of Russian history (tsarism and Soviet era) met on the artistic platform of the modern cinematography of Russia.

The chronological perspective is present also in the paper of Sabina Giergiel and Katarzyna Taczyńska who analyze the problem of the "borderline of memory, forgetting and oblivion" in Filip David's works which can be treated as examples of the contemporary discourse on the Holocaust in Serbian literature. This paper shows how the issue of border can be used in memory studies, recalling such specific examples of borderlines as the 
borderline of responsibility, borderline between guilt and lack of guilt, as well as the borderlines of evil or identity. All of those notions can be labeled as multiple borders of human civilization, even if they cannot be precisely drawn in the context of political or cultural space, or historical chronology.

The thematic section of this issue contains also a paper written by John Cox which to some extent raises all the above-mentioned problems. The paper is devoted to the issue of the binaries and borders in the Provincial Philosophy of Radomir Konstantinović and shows how this specific author, essential for the modern intellectual and cultural history of Serbia, defined various borders placed on the axis of values, time, and geography. Those borders were to be found either in the vast context of the relations of Serbia with the rest of Europe, but also in a more narrow context of the relations between the provincial and the urban sphere.

Although the articles which form this thematic section of Colloquia Humanistica belong to various thematic fields, they all seem to touch upon one common aspect. All of them show that the issue of the borders of civilization was rarely exclusive, and thus it cannot be simply treated in the context of division and separation. More often its inclusiveness was emphasized, which aspect was visible in such notions as fluent transitions and mutual exchange. The presence of such an approach in almost all of the papers should not be surprising: all of the authors investigated the issue from the very close perspective, which allowed them to perceive the border rather as a part of a more or less defined strip of space or time, than as a dividing line.

\section{Note}

Wojciech Sajkowski, Institute of History, Adam Mickiewicz University in Poznań, Poznań.

wojciech.sajkowski@amu.edu.pl

The preparation of the article was self-funded by the author.

No competing interests have been declared. 
